\title{
In Vitro and Ex Vivo Chemopreventive Action of Mauritia flexuosa Products
}

\author{
Joilane Alves Pereira-Freire, ${ }^{1,2}$ George Laylson da Silva Oliveira, ${ }^{3}$ \\ Layana Karine Farias Lima, ${ }^{2}$ Carla Lorena Silva Ramos, ${ }^{2}$ Stella Regina Arcanjo-Medeiros, ${ }^{1}$ \\ Ana Cristina Silva de Lima, ${ }^{4}$ Sabrina Almondes Teixeira, ${ }^{5}$ \\ Guilherme Antônio Lopes de Oliveira, ${ }^{2}$ Nárcia Mariana Fonseca Nunes, ${ }^{2,6}$ \\ Vivianne Rodrigues Amorim, ${ }^{2,6}$ Luciano da Silva Lopes, ${ }^{2,6}$ Larissa Araújo Rolim (D), ${ }^{7}$ \\ Joaquim Soares da Costa-Júnior, ${ }^{8}$ and Paulo Michel Pinheiro Ferreira $\mathbb{D}^{2,6}$ \\ ${ }^{1}$ Department of Nutrition, Federal University of Piauí, 64607-670 Picos, Brazil \\ ${ }^{2}$ Postgraduate Programs in Pharmaceutical Sciences and Biotechnology, Federal University of Piauí, 64049-550 Teresina, Brazil \\ ${ }^{3}$ Department of Biology, Center for Higher Studies of Coelho Neto, State University of Maranhão, 65620-000 Coelho Neto, Brazil \\ ${ }^{4}$ Postgraduate Program in Biotechnology, Federal University of Ceará, 60020-181 Fortaleza, Brazil \\ ${ }^{5}$ Postgraduate Program in Foods and Nutrition, Federal University of Piaui, 64049-550 Teresina, Brazil \\ ${ }^{6}$ Department of Biophysics and Physiology, Laboratory of Experimental Cancerology, Federal University of Piaui, \\ 64049-550 Teresina, Brazil \\ ${ }^{7}$ Department of Pharmaceutical Sciences, Federal University of Vale do São Francisco, 56304-205 Petrolina, Brazil \\ ${ }^{8}$ Federal Institute of Piauí, 64000-060 Teresina, Brazil
}

Correspondence should be addressed to Paulo Michel Pinheiro Ferreira; pmpf@ufpi.edu.br

Received 5 February 2018; Revised 14 April 2018; Accepted 2 May 2018; Published 3 June 2018

Academic Editor: Sérgio Faloni De Andrade

Copyright (C) 2018 Joilane Alves Pereira-Freire et al. This is an open access article distributed under the Creative Commons Attribution License, which permits unrestricted use, distribution, and reproduction in any medium, provided the original work is properly cited.

\begin{abstract}
Mauritia flexuosa (Arecaceae), known as "Buriti," is a Brazilian palm tree with high economic potential for local communities. Herein, we investigated the phytochemistry profile and antioxidant potential of $M$. flexuosa fruits and determined the bioaccessibility of phenolic compounds. Peels revealed upper values for phenols, flavonoids, carotenoids, tannins, and ascorbic acid when compared to the pulps and endocarps. All samples showed capacity to scavenger free radicals $(0.5,1.0,2.0,4.0$, and $8.0 \mathrm{mg} / \mathrm{mL}$ ) but peels presented higher scavenger action in all methods explored. Phenolic compounds identified by HPLC displayed reduced bioaccessibility after in vitro simulated gastrointestinal digestion for pulp (38.7\%), peel (18.7\%), and endocarp (22.3\%) extracts $(P<0.05)$. Buriti fruits also protected rat blood cells against lysis induced by peroxyl radicals. We demonstrated the promising chemopreventive potentialities of $M$. flexuosa fruits and their by-products and peels with higher quantities of bioactive compounds and phenolic substances before and after in vitro bioaccessibility investigation. In Brazil, these parts are discarded or underused, mainly as feed for ruminant animals. Consequently, it is extremely important to explore nutritional characteristics of these by-products for human/livestock foods and to install biofriendly techniques and sustainable biotechnology handling of natural resources.
\end{abstract}

\section{Introduction}

Bioactive compounds have natural functions in plants such as sensory properties (color, aroma, flavor, and astringency) and defense against microorganisms and predators [1]. On the other hand, intake of vegetal nutrients has functional benefits for consumers and enables increasing supply for healthy foods. A diet rich in antioxidant compounds associated with endogenous enzymatic mechanisms can help to minimize the development of oxidative damage caused 
by free radicals (free electrons), mainly reactive oxygen (ROS)/nitrogen (RNS)/sulfur (RSS)/and chlorine species, since these unstable molecules are consequence of normal and/or unbalanced metabolic activities and studies have demonstrated epidemiological and biological correlations with chronic or nonchronic diseases such as hypercholesterolemia, atherosclerosis, hypertension, ischemiareperfusion injury, inflammation, cystic fibrosis, diabetes, Parkinson's disease, Alzheimer, cancer, and aging process itself or premature aging [2-8].

In this context, plant species produce secondary metabolites belonging to different chemical groups such as alkaloids and cyanogenic glycosides and nonnitrogenous compounds, such as tannins, flavonoids, terpenes, and anthocyanins, which present antioxidant activity [9-12].

"Buriti," Mauritia flexuosa L. f., belongs to the family Arecaceae, a palm tree widely distributed in South America, especially in the Amazon region and Brazilian Cerrado, where it has demonstrated high economic potential for the biotechnology development based on the sustainability of natural resources. In the Brazilian food industry, the peel and endocarp are commonly discarded or underutilized for the preparation of candies, ice creams, juices, jams, porridges, and/or oils [13]. Additionally, some studies have emphasized pharmacological potentialities of the M. flexuosa parts, such as antimicrobial [14-16], antitumor [16], hypolipemiant [17], hypoglycemiant [18], and healing activities [19].

For exotic and underexploited plants, in particular, there is little and shallow knowledge about key interfering factors in the biological significance of foods on human health, intake of nutrients, and their bioaccessibility/bioavailability throughout the gastrointestinal tract $[20,21]$. In this perspective, the development of studies on the use of regional and tropical fruits should be encouraged, advancing about the knowledge and exploring the use of fresh fruits for Research and Development (R\&D) of novel products [22, 23]. Herein, we investigated the phytochemistry profile and antioxidant potential of $M$. flexuosa fruits and determined the bioaccessibility of phenolic compounds using in vitro simulated gastrointestinal digestion.

\section{Materials and Methods}

2.1. Chemical Reagents. Chemical reagents 2,2-diphenyl-1picrylhydrazyl $\left(\mathrm{DPPH}^{\bullet}\right), 2,20$-azino-bis(3-ethylbenzothiazoline-6-sulfonic acid) ( ABTS $^{\circ+}$ ), thiobarbituric acid, trichloroacetic acid, ferric chloride, potassium ferricyanide, dihydrochloride 2,2' -azobis(2-amidinopropane) dihydrochloride (AAPH), sodium nitroprusside (SNP), Triton X-100, FolinCiocalteu, sodium carbonate, gallic acid, aluminum chloride, quercetin, $\beta$-carotene, potassium iodide, and potassium persulfate were obtained from Sigma-Aldrich Co. (St. Louis, MO, USA).

2.2. Plant Material: Origin and Preparation. A sample of Mauritia flexuosa was deposited in the Graziela Barroso Herbarium at Federal University of Piauí (UFPI) (voucher specimen \#30567). About 300 fruits were collected in Água Branca, Piauí, Brazil, in December 2014 (latitude: $5^{\circ} 54^{\prime} 50.5^{\prime \prime} \mathrm{S}$; longitude: $42^{\circ} 38^{\prime} 03.4^{\prime \prime} \mathrm{W}$ ) and taken to the Federal Institute of Piauí, Teresina, Brazil. Fruits were selected regarding sanity and same maturation stage and cleaned in water containing $25 \mathrm{ppm}$ of commercial sodium hypochlorite. These fruits presented an elongated oval shape surrounded by the epicarp (peel) of reddish brown color, mesocarp (pulp), orange, and endocarp with a white or yellowish spongy tissue [24]. Subsequently, fruits were separated in pulp, peel, and endocarp. These parts were frozen separately at $-70^{\circ} \mathrm{C}$. For the lyophilization process, stainless steel tray of lyophilizer model L101 (Liotop, São Carlos, Brazil) was used. Lyophilization conditions (temperature: $40^{\circ} \mathrm{C}$; vacuum pressure: $<500 \mathrm{mmHg}$; lyophilization rate: $1 \mathrm{~m} / \mathrm{h}$ ) were well controlled during $72 \mathrm{~h}$ [25]. After such process, fruits were packaged in plastic bags under refrigeration at $4^{\circ} \mathrm{C}$ before process for preparation of powder samples using rotor mill $(0.08 \mathrm{~mm})$ (Figure 1).

2.3. Content of Phenols, Flavonoids, Carotenoids, Tannins, and Ascorbic Acid. Pulverized pulp, peel, and endocarp samples were submitted to extraction of bioactive compounds with methanol. Samples were mixed with mortar and pestle for $10 \mathrm{~min}$ (1:10; sample/solvent) until reaching uniform consistency. Methanol extracts were stored at $4^{\circ} \mathrm{C}$ for 2 days up to quantification of bioactive compounds (phenols, flavonoids, carotenoids, and tannins) and antioxidant activity, respectively. All analyses of bioactive compounds were carried out in quintuplicate.

2.3.1. Total Phenolics. The total phenolic content was determined with Folin-Ciocalteu reagent according to [3], with some modifications. For $1 \mathrm{~mL}$ of pulp, peel, and endocarp methanol solution $(10 \mathrm{mg} / \mathrm{mL}), 1 \mathrm{~mL}$ of Folin-Ciocalteu reagent $(1: 4)$ and $1 \mathrm{~mL}$ of $15 \%$ sodium carbonate $\left(\mathrm{Na}_{2} \mathrm{CO}_{3}\right)$ were added and the final volume was filled with distilled water to $10 \mathrm{~mL}$. The mixture was maintained for $2 \mathrm{~h}$ and centrifuged at $4000 \mathrm{rpm}$ during $4 \mathrm{~min}$. The supernatant was measured at $750 \mathrm{~nm}$. Stock solution without fruit parts was used as negative control. Results were expressed as mg of gallic acid equivalents per $100 \mathrm{~g}$ of sample (mg GAE/100 g sample) and a gallic acid calibration curve was determined (0.9497x $y=-$ $\left.0.0527 ; r^{2}=0.999\right)$.

2.3.2. Total Flavonoids. The content of total flavonoids was determined based on the formation of the flavonoidaluminum complex, according to [3] with some modifications. For $1 \mathrm{~mL}$ of pulp, peel, and endocarp methanol solution $(10 \mathrm{mg} / \mathrm{mL}), 1 \mathrm{~mL}$ of $20 \%$ aluminum chloride and $100 \mu \mathrm{L}$ of $50 \%$ acetic acid were added. The mixture was maintained for $30 \mathrm{~min}$ and centrifuged at $4000 \mathrm{rpm}$ during $4 \mathrm{~min}$. The supernatant was measured at $420 \mathrm{~nm}$. Results were expressed as $\mathrm{mg}$ of quercetin equivalent per $100 \mathrm{~g}$ of sample (mg $\mathrm{EQE} / 100 \mathrm{~g}$ sample) and a quercetin calibration curve was prepared $\left(y=0.0136 x-0.0422 ; r^{2}=0.999\right)$.

2.3.3. Total Carotenoids. Total carotenoids were determined according to [26] with some modifications. A total of $0.1 \mathrm{~g}$ of pulp, peel, and endocarp diluted in $10 \mathrm{~mL}$ of acetone : hexane solution $(4: 6)$ was stirred for $10 \mathrm{~min}$ at room temperature 


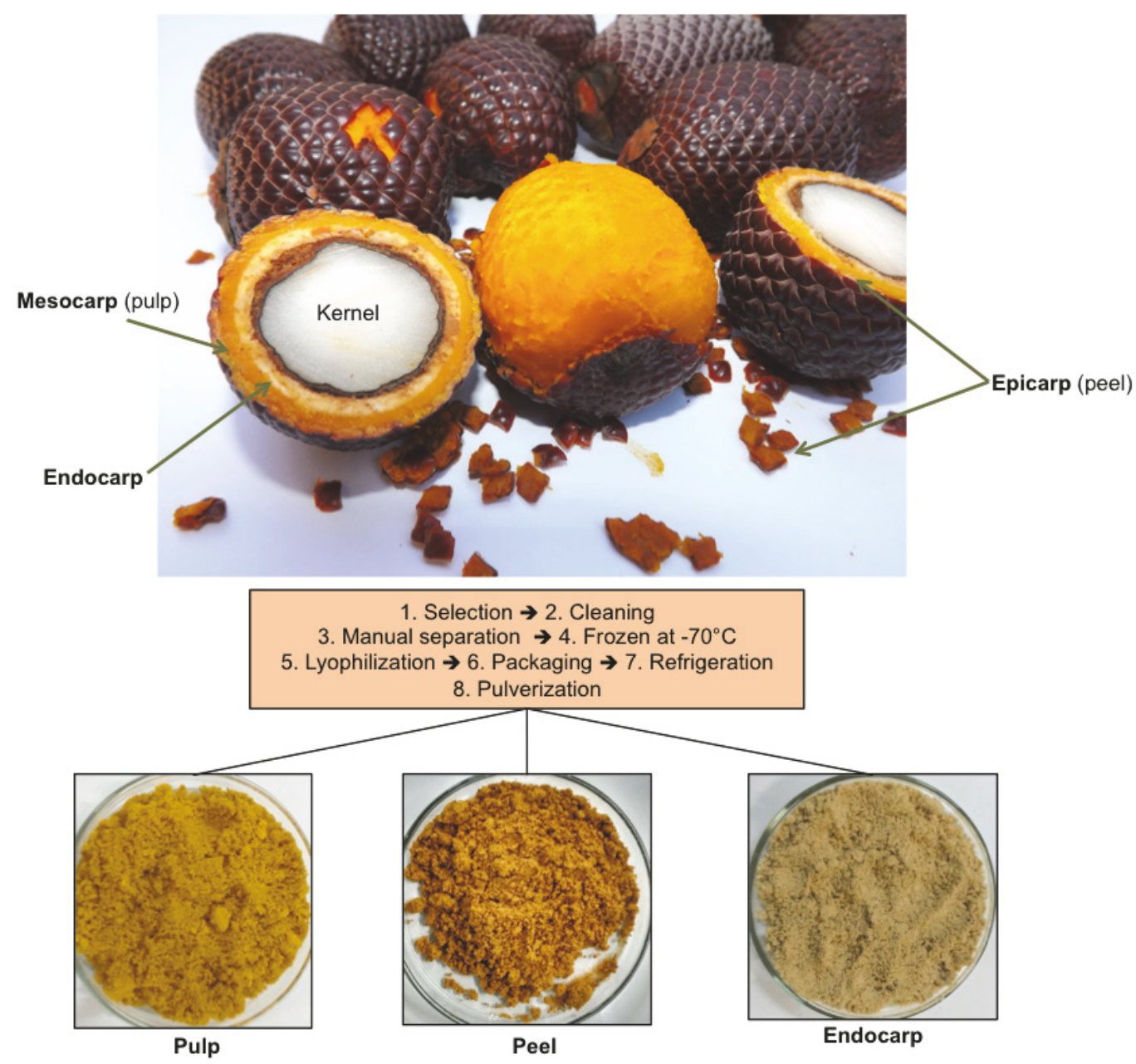

FIGURE 1: Preparation of Mauritia flexuosa fruits: lyophilization, pulverization, and stocking preceded phytochemical and biological analysis.

(400 rpm) and centrifuged for $4 \mathrm{~min}$ at $4000 \mathrm{rpm}$. Reading was performed at $450 \mathrm{~nm}$ and the results were expressed as $\mathrm{mg}$ of $\beta$-carotene equivalent per $100 \mathrm{~g}$ of sample $(\mathrm{mg}$ $\beta$ CTE $/ 100 \mathrm{~g}$ sample). A $\beta$-carotene calibration curve was prepared $\left(y=0.3099 x-0.341 ; r^{2}=0.991\right)$.

2.3.4. Condensed Tannins. The content of condensed tannins was determined using the methodology of vanillin [27]. To the methanol solution containing $1 \mathrm{~mL}$ of pulp, peel, and endocarp $(10 \mathrm{mg} / \mathrm{mL}), 3 \mathrm{~mL}$ of $2 \%$ vanillin prepared with sulfuric acid (70\%) was added. Subsequently, the reaction mixture was performed in water bath at $20^{\circ} \mathrm{C}$ for $15 \mathrm{~min}$. Samples were centrifuged for $4 \mathrm{~min}$ at $4000 \mathrm{rpm}$ and reading was carried out in digital spectrophotometer at $500 \mathrm{~nm}$. Results were expressed as milligrams of catechin equivalents per gram of sample (mg CTQ/100 g sample). A catechin calibration curve was performed $\left(y=0.008 x+0.096 ; r^{2}=\right.$ 0.999).

2.3.5. Hydrolysable Tannins. The hydrolysable tannin concentration was determined using potassium iodide according to [28]. One milliliter of saturated potassium iodide solution was added to the methanol solution containing $3 \mathrm{~mL}$ of pulp, peel, and endocarp $(10 \mathrm{mg} / \mathrm{mL})$ and allowed to rest at room temperature for $40 \mathrm{~min}$ and centrifuged for 4 minutes at $4000 \mathrm{rpm}$ and the absorbance was measured at $550 \mathrm{~nm}$. Results were expressed as mg of tannic acid equivalents per gram of sample (mg ACT/100 g sample) and a tannic acid calibration curve $\left(0.0122 x+y=0.26 ; r^{2}=0.981\right)$ was performed.

2.3.6. Ascorbic Acid. Ascorbic acid content was determined using the titrimetric Tillmans' method. We used a solution of oxalic acid as a solvent to substitute metaphosphoric acid. Twenty milliliters was mixed with $80 \mathrm{~mL}$ of $1 \%$ oxalic acid and $10 \mathrm{~mL}$ of such solution was titrated with Tillmans reagent, using 2,6-dichlorophenolindophenol. Results were calculated based on a standard solution of ascorbic acid and expressed in $\mathrm{mg} / 100 \mathrm{~mL}$.

2.4. In Vitro Quantification of Total Phenolics after Simulated Gastrointestinal Digestion. The digestion was performed using simulated gastric (pepsin solubilized with $0.1 \mathrm{~mol} / \mathrm{L}$ $\mathrm{HCl}$ ) and intestinal fluids (pancreatin-bile salts solubilized with $0.1 \mathrm{~mol} / \mathrm{L} \mathrm{NaHCO}_{3}$ ), which were prepared according to [29]. We added $1 \mathrm{~mL}$ of pulp, peel, and endocarp methanol 
solution $(10 \mathrm{mg} / \mathrm{mL})$ to $100 \mathrm{~mL}$ of $0.01 \mathrm{~mol} / \mathrm{L} \mathrm{HCl}$, and $\mathrm{pH}$ was adjusted to 2 with $2 \mathrm{~mol} / \mathrm{L} \mathrm{HCl}$ solution. Equal quantity of phenols was used as positive control $(10 \mathrm{mg} / \mathrm{mL})$. Afterwards, $3.2 \mathrm{~mL}$ of pepsin was added, maintaining samples under stirring at $37^{\circ} \mathrm{C}$ for $2 \mathrm{~h}$ to simulate food digestion in the stomach. Then, to simulate the $\mathrm{pH}$ found in human intestines, titration was carried out with $0.5 \mathrm{~mol} / \mathrm{L} \mathrm{NaOH}$ to obtain $\mathrm{pH}$ 7.5. Subsequently, a dialysis process was performed for $2 \mathrm{~h}$ (dialysis membrane with $33 \times 21 \mathrm{~mm}$, molecular weight of 12.000 to 16.000 , and porosity of 25 angstroms, Inlab, Brazil) with $0.1 \mathrm{~mol} / \mathrm{L} \mathrm{NaHCO}_{3}$ equivalent to titratable acidity. After $\mathrm{pH}$ adjustment, dialysis membranes were added and the solution was stirred in water bath at $37^{\circ} \mathrm{C} / 30 \mathrm{~min}$. Then, $5 \mathrm{~mL}$ of pancreatin-bile salts solution was added and the mixture was stirred again for additional $2 \mathrm{~h}$ to mimic food digestion in the intestine. Finally, the membrane content (dialysate) was removed and samples were stored at $20^{\circ} \mathrm{C}$ until analysis.

Finally, dialyzed material was analyzed to determine total phenolics [3]. Results were expressed as mg gallic acid/100 g sample. The bioaccessible percentage was calculated according to [20]: \% bioaccessible $=100 \times(\mathrm{DPC} / \mathrm{CPC})$, where $\mathrm{F}$ is the content of dialyzable phenolic compounds (mg gallic acid/100 g sample) and $G$ corresponds to the content of phenolic compounds in the sample ( $\mathrm{mg}$ gallic acid/100 $\mathrm{g}$ sample).

2.5. In Vitro Antioxidant Capacity. For in vitro antioxidant evaluation, the antioxidant capacity of the samples was assayed against 1,1-diphenyl-2-picrylhydrazyl [DPPH $\left.{ }^{*}\right]$ [30], 2,2'-azino-bis(3-ethylbenzothiazoline-6-sulphonic acid $\left[\mathrm{ABTS}^{\circ+}\right]$ [31], reducing potential $\left[\mathrm{Fe}^{3+} / \mathrm{Fe}^{2+}\right]$ [32], lipid peroxidation [thiobarbituric acid reactive substances (TBARS) removal [33,34], and nitrite content [nitrite production induced by sodium nitroprusside [35, 36]. Aqueous stock solutions of the samples (pulp, peel, and endocarp: 0.5, 1.0, 2.0, 4.0, and $8.0 \mathrm{mg} / \mathrm{mL})$, DPPH $(40 \mu \mathrm{g} / \mathrm{mL}), \mathrm{ABTS}^{*+}$ $(7 \mathrm{mM}), 1 \%$ potassium ferricyanide, sodium nitroprusside $(10 \mathrm{mM})$, and $0.67 \%$ thiobarbituric acid, were prepared. Trolox $(0.5 \mathrm{mg} / \mathrm{mL})$ was used as positive standard.

Values of $50 \%$ effective concentration $\left(\mathrm{EC}_{50}\right)$ for Buriti extracts were spectrophotometrically quantified (T80+ UV/VIS Spectrometer, PG Instruments Ltd. ${ }^{\circledR}$, Leicestershire, UK) at $515 \mathrm{~nm}$ for $\mathrm{DPPH}^{\circ}, 734 \mathrm{~nm}$ for $\mathrm{ABTS}^{*+}, 700 \mathrm{~nm}$ for potassium ferricyanide, $532 \mathrm{~nm}$ for TBARS (thiobarbituric acid reactive substances), and $540 \mathrm{~nm}$ for nitrite radicals $30 \mathrm{~min}$ after the reaction started. Antioxidant evaluation was performed in triplicate from two independent experiments and absorbance values were converted to the inhibition percentage (I) of radicals using the equation of [37]: (\%) = [(absorbance of negative control - absorbance of sample) $\times$ $100]$ /absorbance of negative control, where absorbance of negative control is, for example, the initial absorbance for $\mathrm{DPPH}^{*}$ solution and absorbance of sample is the absorbance for reaction mixture ( $\mathrm{DPPH}^{\bullet}$ and sample).

2.6. Ex Vivo Analysis on Murine Erythrocytes. All procedures were approved by the Committee on Animal Research at UFC (\#054/2014) and they are in accordance with Brazilian (COBEA, Colégio Brasileiro de Experimentação Animal) and international guidelines on the care and use of experimental animals (Directive 2010/63/EU of the European Parliament and of the Council).

Blood was collected from retroorbital plexus of anesthetized female Wistar rats (180-220 g) with ketamine $(90 \mathrm{mg} / \mathrm{kg}$, i.p.) and xylazine $(10 \mathrm{mg} / \mathrm{kg}$, i.p.). Blood was mixed with $0.85 \% \mathrm{NaCl}$ solution containing $10 \mathrm{mM} \mathrm{CaCl}$ and submitted to three centrifugations $(2000 \mathrm{rpm} / 5 \mathrm{~min}$ ). Erythrocytes were suspended in $\mathrm{NaCl}$ to obtain a cell suspension (10\%). Hemolytic investigations were performed in 96-well plates following the method described by [38].

2.6.1. Hemolytic Capacity Determination. Each well received $50 \mu \mathrm{L}$ of $0.85 \% \mathrm{NaCl}$. The first well was the negative control that contained only the vehicle (PBS), and in the second well $50 \mu \mathrm{L}$ of test substance that was diluted in half was added. The extracts were tested at concentrations ranging from 0.5 to $8 \mathrm{~g} / \mathrm{mL}$. The last well received $50 \mu \mathrm{L}$ of $0.2 \%$ Triton X100 (in $0.85 \%$ saline) to obtain $100 \%$ hemolysis. Then, each well received $50 \mu \mathrm{L}$ of a $10 \%$ suspension of mice erythrocytes in $0.85 \%$ saline containing $10 \mathrm{mM} \mathrm{CaCl}_{2}$. After incubation at room temperature for $2 \mathrm{~h}$, cells were centrifuged, the supernatant was removed, and the liberated hemoglobin was measured spectroscopically as absorbance at $540 \mathrm{~nm}$. For comparison, a solution of $0.5 \mathrm{mg} / \mathrm{mL}$ Triton X-100 was used as positive control.

2.6.2. Antioxidant Capacity against Oxidative Hemolysis. The antioxidant capacity against oxidative hemolysis was performed by inhibition of oxidative hemolysis induced by peroxyl radicals generated following thermal decomposition of 2,2 -azobis(2-amidinopropane) dihydrochloride (AAPH) in method described by [39] with some modifications. Briefly, aliquots of pulp, peel, and endocarp aqueous extracts $(0.5$ to $8 \mathrm{mg} / \mathrm{mL}$ ) were mixed with $30 \mu \mathrm{L}$ of $10 \%$ erythrocyte suspension and $50 \mu \mathrm{L}$ of AAPH (200 mM in PBS, pH 7.4) in 96-well plates. The reaction mixture was incubated for 120 minutes at $37^{\circ} \mathrm{C}$. Afterwards, the reaction mixture was diluted with $240 \mu \mathrm{L}$ of PBS and centrifuged at $2000 \mathrm{rpm}$ for $5 \mathrm{~min}$ and the liberated hemoglobin was measured spectroscopically as absorbance at $540 \mathrm{~nm}$. Results were expressed as percentage inhibition of hemolysis compared to the complete hemolysis of erythrocyte suspensions induced by AAPH. Liberated hemoglobin was measured spectroscopically as absorbance at $540 \mathrm{~nm}$. The inhibition of erythrocyte hemolysis was calculated as $\left(1-A_{\text {sample }} / A_{\text {control }}\right) \times 100 \%$. Trolox $(0.5 \mathrm{mg} / \mathrm{mL})$ was used as positive standard.

2.7. Chromatographic Analysis. For chromatographic analysis, methanol extracts of pulp, peel, and endocarp were used. Mobile phases were represented by solvents $\mathrm{A}-\mathrm{C}$ using three pumps associated with the chromatograph (Shimadzu ${ }^{\circledR}$ liquid chromatograph with a diode array detector, Japan: solvent $\mathrm{A}, 0.1 \%$ trifluoroacetic acid in acetonitrile; solvent $\mathrm{B}, 0.1 \%$ trifluoroacetic acid in HPLC grade water; solvent C, $100 \%$ methanol). A TSK-GEL Super-ODS (Supelco) column was used. The effluent was monitored at 250 and $330 \mathrm{~nm}$. Flow rate was fixed at $1.0 \mathrm{~mL} / \mathrm{min}$, and column temperature was maintained at $37^{\circ} \mathrm{C}$ throughout the test. Initially, the solvent 
TABLE 1: Quantification of phenols, flavonoids, carotenoids, condensed tannins, and hydrolysable tannins in the lyophilized methanolic extracts of pulp, peel, and endocarp from Mauritia flexuosa fruits.

\begin{tabular}{|c|c|c|c|}
\hline $\begin{array}{l}\text { Class of } \\
\text { compounds }\end{array}$ & Pulp & Peel & Endocarp \\
\hline $\begin{array}{l}\text { Total phenols } \\
(\mathrm{mg} \text { GAE/100 g) }\end{array}$ & $553.5 \pm 7.7^{\mathrm{b}}$ & $1288.0 \pm 10.4^{\mathrm{a}, \mathrm{c}}$ & $597.1 \pm 6.5^{\mathrm{b}}$ \\
\hline $\begin{array}{l}\text { Total flavonoids } \\
\text { (mg EQE/100 g) }\end{array}$ & $264.4 \pm 2.1^{\mathrm{b}, \mathrm{c}}$ & $339.4 \pm 3.9^{\mathrm{a}, \mathrm{c}}$ & $145.4 \pm 10.2^{\mathrm{a}, \mathrm{b}}$ \\
\hline $\begin{array}{l}\text { Total carotenoids } \\
(\mathrm{mg} \beta \mathrm{CTE} / 100 \mathrm{~g})\end{array}$ & $58.9 \pm 0.1^{\mathrm{b}, \mathrm{c}}$ & $88.3 \pm 0.3^{\mathrm{a}, \mathrm{c}}$ & $19.1 \pm 0.2^{\mathrm{a}, \mathrm{b}}$ \\
\hline $\begin{array}{l}\text { Hydrolysable } \\
\text { tannins } \\
\text { (mg ACT/100 g) }\end{array}$ & $47.4 \pm 0.3^{\mathrm{b}, \mathrm{c}}$ & $56.2 \pm 0.4^{\mathrm{a}, \mathrm{c}}$ & $0.1 \pm 0.02^{\mathrm{a}, \mathrm{b}}$ \\
\hline $\begin{array}{l}\text { Condensed tannins } \\
(\mathrm{mg} C \mathrm{CTQ} / 100 \mathrm{~g})\end{array}$ & $69.6 \pm 1.8^{\mathrm{b}, \mathrm{c}}$ & $118.3 \pm 2.1^{\mathrm{a}, \mathrm{c}}$ & $36.5 \pm 1.4^{\mathrm{a}, \mathrm{b}}$ \\
\hline $\begin{array}{l}\text { Ascorbic acid } \\
(\mathrm{mg} / 100 \mathrm{~mL})\end{array}$ & $4.3 \pm 1.3^{\mathrm{c}}$ & $5.9 \pm 0.2^{c}$ & $2.5 \pm 0.3^{\mathrm{a}, \mathrm{b}}$ \\
\hline
\end{tabular}

Data were presented as mean \pm standard error of the mean (SEM). ${ }^{\mathrm{a}} P<0.05$ compared to pulp; ${ }^{\mathrm{b}} P<0.05$ compared to peel; ${ }^{\mathrm{c}} P<0.05$ compared to endocarp by ANOVA followed by Student-Newman-Keuls test.

was represented by $100 \%$ solvent $\mathrm{B}$, but a linear gradient was used to increase solvent A from 0 to $10 \%$ within $7 \mathrm{~min}$. Its composition was maintained at an isocratic flow for $3 \mathrm{~min}$. Then, solvent A increased from 10 to $40 \%$ during $20 \mathrm{~min}$. Such composition was maintained for additional $2 \mathrm{~min}$ and returned to the initial condition in $3 \mathrm{~min}$. A volume of $20 \mu \mathrm{L}$ for the standards substances and samples was injected for each HPLC analysis.

2.8. Statistical Analysis. Data were presented as mean \pm standard error of the mean (SEM) and compared by oneway analysis of variance (ANOVA) followed by StudentNewman-Keuls test using GraphPad Prism ${ }^{\circledR}$ software 5.0 (San Diego, CA, USA). $\mathrm{EC}_{50}$ values were calculated by nonlinear regression (95\%). Statistical correlation among experimental data was performed using the Pearson coefficient $(r)$ and results were statistically significant when $P<0.05$.

\section{Results}

3.1. Bioactive Compounds and Bioaccessibility. The screening of bioactive compounds in $M$. flexuosa fruit is described in Table 1. Peel revealed the highest values for phenols $(1288.0 \pm 10.4 \mathrm{mg}$ GAE$/ 100 \mathrm{~g})$, flavonoids $(339.4 \pm 3.9 \mathrm{mg}$ $\mathrm{EQE} / 100 \mathrm{~g})$, carotenoids $(88.3 \pm 0.3 \mathrm{mg} \beta \mathrm{CTE} / 100 \mathrm{~g})$, tannins (hydrolysable: $56.2 \pm 0.4 \mathrm{mg}$ ACT/100 g; condensed: $118.3 \pm$ $2.1 \mathrm{mg}$ CTQ/100 g), and ascorbic acid $(5.9 \pm 0.2 \mathrm{mg} / 100 \mathrm{~mL})$ when compared to the pulp and endocarp $(P<0.05)$.

The correlation of chromatographic peaks was achieved by comparison of experimental retention times $\left(t_{R}\right)$ with reference standards (Table 2). All chromatographic analyses were carried out in triplicate and revealed phenolic compounds (protocatechuic acid, quercetin, apigenin, catechin, and epicatechin) with the following $t_{R}: 16.3,33.6,41.7,53.6$, and 49.3 minutes, respectively.
Subsequently, we analyzed the quantity of phenolic compounds before and after in vitro simulated gastrointestinal digestion for pulp, peel, and endocarp (Table 3). All samples (pulp, peel, and endocarp) displayed reduction in bioaccessibility after in vitro digestion of $38.7,18.7$, and $22.3 \%$, respectively $(P<0.05)$.

3.2. In Vitro Antioxidant Capacity. In this step, we carried out quantification of the antioxidant capacity of Buriti samples (pulp, peel, and endocarp) at concentrations of $0.5,1,2,4$, and $8 \mathrm{mg} / \mathrm{mL}$. This capacity is described as free radical inhibition (Figure 2).

For all parameters and samples, we determined $\mathrm{EC}_{50}$ values: $1.6 \pm 0.1,0.1 \pm 0.1$, and $1.5 \pm 0.1 \mathrm{mg} / \mathrm{mL}\left(\mathrm{DPPH}^{\circ}\right)$; $2.3 \pm 0.1,0.1 \pm 0.1$, and $1.9 \pm 0.1 \mathrm{mg} / \mathrm{mL}\left(\mathrm{ABTS}^{\bullet+}\right) ; 2.1 \pm 0.3$, $1.2 \pm 0.1$, and $1.9 \pm 0.4 \mathrm{mg} / \mathrm{mL}$ (potassium ferricyanide); $1.6 \pm 0.2,0.7 \pm 0.1$, and $2.3 \pm 0.2 \mathrm{mg} / \mathrm{mL}$ (TBARS); and 2.6 \pm 0.1 , $1.1 \pm 0.1$, and $6.4 \pm 0.14 \mathrm{mg} / \mathrm{mL}$ (nitrite content) for pulp, peel, and endocarp, respectively. Trolox $(0.5 \mathrm{mg} / \mathrm{mL})$, the positive standard, showed free radical inhibition capacity upper to $90 \%$ for the antioxidant assessments (Figure 2). Then, all samples showed growing capacity in a concentration-dependent manner to scavenger free radicals, but it is important to note that peels' samples presented a higher scavenger capacity in all methods explored $(P<0.05)$.

3.3. Antioxidant Capacity against Oxidative Hemolysis. Firstly, we analyzed the capacity of the samples to cause hemolysis. None of the extracts induced lysis of rat erythrocytes even $8.0 \mathrm{mg} / \mathrm{mL}$. On the other hand, Triton $\mathrm{X}-100$, used as positive control, caused $100 \%$ hemolysis.

Based on these promising findings (scavenger of free radicals and absence for cellular lysis), we evaluated the antioxidant capacity against oxidative hemolysis induced by AAPH (100\% hemolysis). Once again, all concentrations 
TABLE 2: Identification of compounds by high-performance liquid chromatography (HPLC) in Mauritia flexuosa samples.

\begin{tabular}{|c|c|c|c|c|}
\hline $\begin{array}{l}\text { IUPAC Name } \\
\text { Chemical Name }\end{array}$ & Chemical structures & Class & $\begin{array}{l}\text { Retention time } \\
\quad(\min )\end{array}$ & Sample \\
\hline $\begin{array}{l}\text { 3,4-Dihydroxybenzoic acid } \\
\text { (protocatechuic acid) }\end{array}$ & & Phenol & 16.3 & Pulp \\
\hline $\begin{array}{l}\text { 2-(3,4-dihydroxyphenyl)- } \\
\text { 3,5,7-trihydroxychromen- } \\
\text { 4-one } \\
\text { (quercetin) }\end{array}$ & & Flavonoid & 33.6 & Pulp \\
\hline $\begin{array}{l}4^{\prime}, 5,7-\text { Trihydroxyflavone } \\
\text { (apigenin) }\end{array}$ & & Flavonoid & 41.7 & $\begin{array}{l}\text { Pulp } \\
\text { Endocarp }\end{array}$ \\
\hline $\begin{array}{l}\text { (-)-trans- } 3,3^{\prime}, 4^{\prime}, 5,7- \\
\text { pentahydroxyflavane, } \\
(2 \mathrm{~S}, 3 \mathrm{R})-2-(3,4- \\
\text { dihydroxyphenyl)-3,4- } \\
\text { dihydro-1(2H)- } \\
\text { benzopyran-3,5,7-triol } \\
\text { (catechin) }\end{array}$ & & Condensed tannin & 53.6 & $\begin{array}{l}\text { Endocarp } \\
\text { Peel } \\
\text { Pulp }\end{array}$ \\
\hline
\end{tabular}

$(-)$-cis- $3,3^{\prime}, 4^{\prime}, 5,7-$ pentahydroxyflavane, $(2 R, 3 R)-2-(3,4-$

dihydroxyphenyl)-3,4dihydro-1 $(2 H)$ -

benzopyran-3,5,7-triol (epicatechin)<smiles>Oc1cc(O)c2c(c1)O[C@H](c1ccc(O)c(O)c1)[C@H](O)C2</smiles>

48.3

Peel

TABLE 3: Contents of phenolic compounds in the lyophilized methanolic extracts of pulp, peel, and endocarp from Mauritia flexuosa fruits before and after simulated gastrointestinal digestion.

\begin{tabular}{lccc}
\hline Sample & $\begin{array}{c}\text { Bioaccessibility before in } \\
\text { vitro digestion } \\
(\mathrm{mg} / \mathrm{L})\end{array}$ & $\begin{array}{c}\text { Bioaccessibility after } \\
\text { in vitro digestion } \\
(\mathrm{mg} / \mathrm{L})\end{array}$ & $\begin{array}{c}\text { Reduction }(\%) \\
\text { Pulp }\end{array}$ \\
Peel & $553.5 \pm 7.7$ & $102.2 \pm 0.4^{*}$ & 18.7 \\
Endocarp & $1288.0 \pm 10.4$ & $498.5 \pm 13.9^{*}$ & 38.7 \\
\hline
\end{tabular}

${ }^{*} P<0.05$ compared to bioaccessibility before in vitro digestionby ANOVA followed by Student-Newman-Keuls test. 


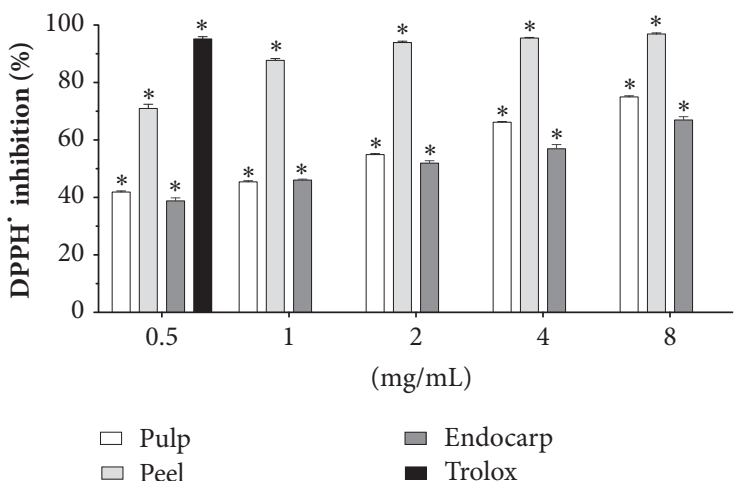

(a)

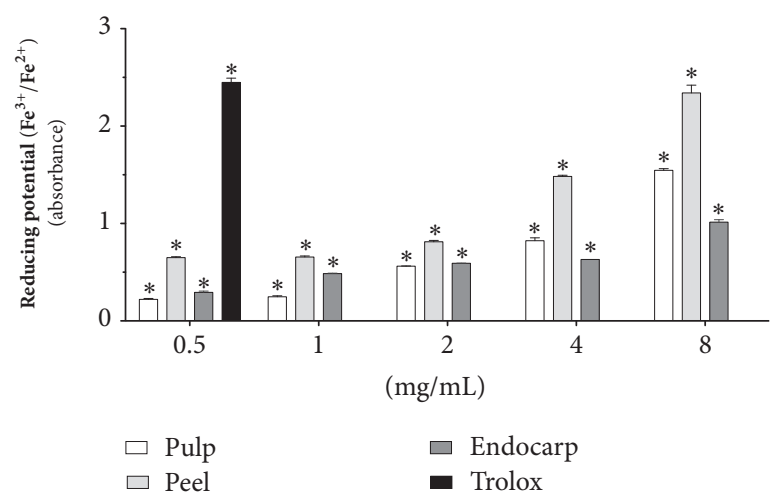

(c)

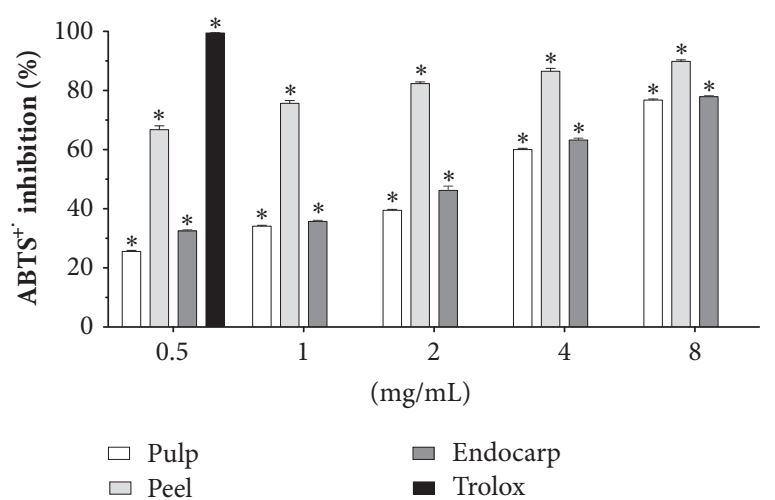

(b)

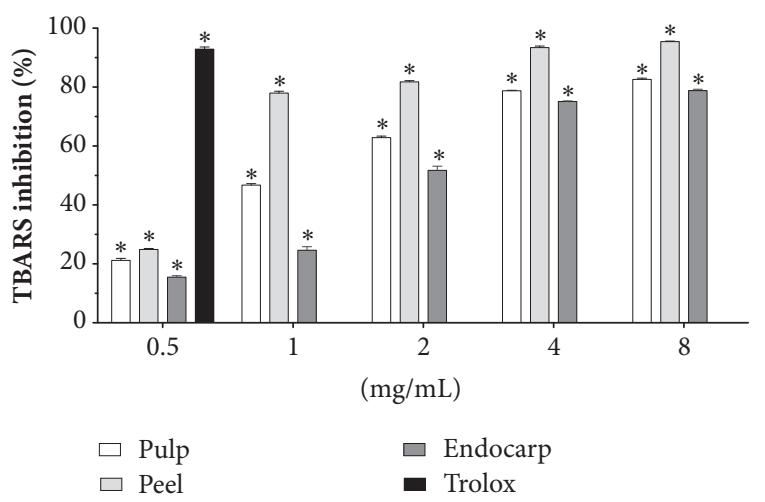

(d)

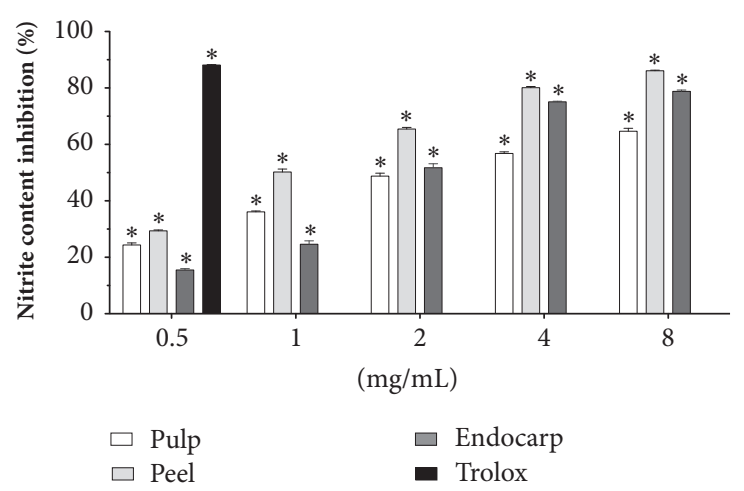

(e)

FIGURE 2: Effects of lyophilized fruits (pulp, peel, and endocarp) from Mauritia flexuosa (0.5, 1, 2, 4, and $8 \mathrm{mg} / \mathrm{mL}$ ) on the removal of (a) 1,1diphenyl-2-picrylhydrazyl (DPPH ${ }^{*}$ ), (b) 2,20-azino-bis(3-ethylbenzothiazoline-6-sulfonic acid) $\left(\mathrm{ABTS}^{++}\right),(\mathrm{c}) \mathrm{reducing}$ potential $\left(\mathrm{Fe}^{3+} / \mathrm{Fe}^{2}\right)$, (d) reactive substances to thiobarbituric acid [TBARS levels induced by $2,2^{\prime}$-azo-bis (2-methylpropionamidine]) dihydrochloride, AAPH), and (e) nitrite content (induced by sodium nitroprusside). Trolox $(0.5 \mathrm{mg} / \mathrm{mL})$ was used as positive standard. Results are expressed as mean \pm standard error of measurement (SEM) from two independent experiments in triplicate. Negative control was treated with the solution used for diluting the tested substance. With exception of reducing potential, absorbance values were converted to inhibition $(I)$ percentage of radicals: $I(\%)=\left[(\right.$ absorbance of negative control - absorbance of sample) $\times 100] /$ absorbance of negative control. ${ }^{*} P<0.05$ compared to negative control by ANOVA followed by Student-Newman-Keuls test.

used $(0.5,1.0,2.0,4.0$, and $8.0 \mathrm{mg} / \mathrm{mL})$ were able to protect blood cells when compared to positive control exposed to peroxyl radicals generated following thermal decomposition of AAPH as follows: pulp $(15.0 \pm 1.1,26.9 \pm 0.7,27.6 \pm 0.4$, $36.8 \pm 0.1$, and $49.3 \pm 2.7 \%)$, peel $(26.9 \pm 0.6,46.9 \pm 1.2,51.2 \pm 0.3$, $60.1 \pm 0.8$, and $74.3 \pm 0.5 \%)$, and endocarp $(19.6 \pm 1.7,25.7 \pm 0.9$, $28.5 \pm 0.3,31.8 \pm 0.5$, and $40.2 \pm 0.7 \%$ ), respectively (Figure 3).
Trolox showed an antioxidant perceptual protection of $73.2 \pm$ $0.5 \%$. $\mathrm{EC}_{50}$ values were $7.7 \pm 0.4,1.8 \pm 0.1$, and $11.4 \pm 0.5 \mathrm{mg} / \mathrm{mL}$ for pulp, peel, and endocarp, respectively.

Pearson's correlation, a measure of the strength of linear relationship between two variables, revealed a positive relationship between bioactive compounds (total phenol, total flavonoids, total carotenoids, and condensed and 
TABLE 4: Analysis of Pearson's correlation among bioactive compounds and antioxidant capacity in samples of pulp, peel, and endocarp from Mauritia flexuosa.

\begin{tabular}{|c|c|c|c|c|c|c|}
\hline Class of compounds & $\mathrm{DPPH}^{\circ}$ & $\mathrm{ABTS}^{\circ+}$ & Reducing potential & TBARS & Nitrite content & Oxidative hemolysis \\
\hline \multicolumn{7}{|c|}{ Pulp } \\
\hline Total phenols & $0.956^{*}$ & $0.978^{*}$ & $0.978^{*}$ & 0.867 & $0.931^{*}$ & $0.954^{*}$ \\
\hline Total flavonoids & $0.957^{*}$ & $0.979^{*}$ & $0.978^{*}$ & 0.869 & $0.933^{*}$ & $0.956^{*}$ \\
\hline Total carotenoids & $0.951^{*}$ & $0.974^{*}$ & $0.975^{*}$ & 0.859 & $0.926^{*}$ & $0.951^{*}$ \\
\hline Condensed tannins & $0.955^{*}$ & $0.977^{*}$ & $0.978^{*}$ & 0.866 & $0.930^{*}$ & $0.954^{*}$ \\
\hline Hydrolysable tannins & $0.923^{*}$ & $0.953^{*}$ & $0.956^{*}$ & 0.822 & $0.898^{*}$ & $0.935^{*}$ \\
\hline \multicolumn{7}{|c|}{ Peel } \\
\hline Total phenols & 0.681 & 0.847 & $0.928^{*}$ & 0.749 & 0.854 & $0.907^{*}$ \\
\hline Total flavonoids & $0.956^{*}$ & $0.978^{*}$ & $0.978^{*}$ & 0.867 & $0.931^{*}$ & $0.954^{*}$ \\
\hline Total carotenoids & $0.966^{*}$ & $0.984^{*}$ & $0.983^{*}$ & $0.881^{*}$ & $0.941^{*}$ & $0.959^{*}$ \\
\hline Condensed tannins & $0.963^{*}$ & $0.982^{*}$ & $0.982^{*}$ & 0.876 & $0.937^{*}$ & $0.957^{*}$ \\
\hline Hydrolysable tannins & $0.972^{*}$ & $0.988^{*}$ & $0.987^{*}$ & $0.890^{*}$ & $0.947^{*}$ & $0.961^{*}$ \\
\hline \multicolumn{7}{|c|}{ Endocarp } \\
\hline Total phenols & 0.682 & 0.848 & $0.930^{*}$ & 0.751 & 0.854 & $0.907^{*}$ \\
\hline Total flavonoids & $0.951^{*}$ & $0.974^{*}$ & $0.975^{*}$ & 0.860 & $0.926^{*}$ & $0.952^{*}$ \\
\hline Total carotenoids & $0.949^{*}$ & $0.973^{*}$ & $0.974^{*}$ & 0.857 & $0.924^{*}$ & $0.950^{*}$ \\
\hline Condensed tannins & $0.952^{*}$ & $0.975^{*}$ & $0.976^{*}$ & 0.861 & $0.927^{*}$ & $0.952^{*}$ \\
\hline Hydrolysable tannins & $0.948^{*}$ & $0.972^{*}$ & $0.973^{*}$ & 0.855 & $0.923^{*}$ & $0.950^{*}$ \\
\hline
\end{tabular}

${ }^{*} P<0.05$. Pearson's correlation coefficient was calculated using Student's $t$-test for all variables at 5\% significance levels. 1,1-Diphenyl-2-picrylhydrazyl $\left(\mathrm{DPPH}^{\bullet}\right), 2,2^{\prime}$-azino-bis(3-ethylbenzothiazoline-6-sulphonic acid (ABTS ${ }^{\bullet+}$ ), reducing potential $\left(\mathrm{Fe}^{3+} / \mathrm{Fe}^{2}\right)$, reactive substances to thiobarbituric acid $\left[\mathrm{TBARS}^{-}\right.$ levels induced by $2,2^{\prime}$-azo-bis (2-methylpropionamidine]) dihydrochloride, AAPH), and nitrite content (induced by sodium nitroprusside).

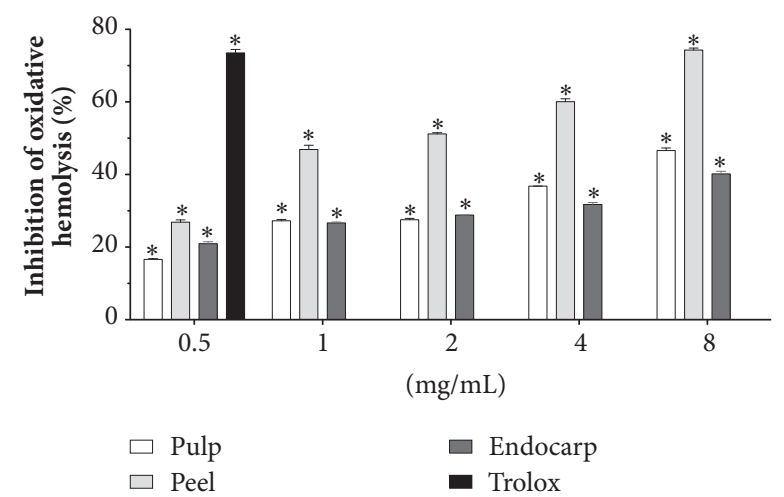

FIGURE 3: Protection against oxidative hemolysis induced by peroxyl radicals generated following thermal decomposition of $2,2^{\prime}$ azobis(2-amidinopropane) dihydrochloride (AAPH) by lyophilized fruits (pulp, peel, and endocarp) from Mauritia flexuosa $(0.5,1,2,4$, and $8 \mathrm{mg} / \mathrm{mL})$. Trolox $(0.5 \mathrm{mg} / \mathrm{mL})$ was used as positive standard. Results are expressed as mean \pm standard error of measurement (SEM) from two independent experiments in triplicate. Negative control was treated with the solution used for diluting the tested substance. ${ }^{*} P<0.05$ compared to control by ANOVA followed by Student-Newman-Keuls test.

hydrolysable tannins) and antioxidant capacity $(r>0.881$; $P<0.05)$ and bioactive compounds and protection against oxidative hemolysis $(r>0.907 ; P<0.05)$ (Table 4$)$. On the other hand, Pearson's correlation did not show association between antioxidant activity against TBARS and presence of bioactive compounds for most correlations analyzed $(P>$ 0.05).

\section{Discussion}

Since oxidative damage contributes significantly to pathologies, herein, we performed different biochemical methods to support the antioxidant and functional action of $M$. flexuosa fruits.

Peels from $M$. flexuosa fruits presented highest values of bioactive compounds when compared to the pulp and endocarps. Previously, studies demonstrated that pulp extracts from Amazon Buriti have mainly quinic acid, caffeic acid, chlorogenic acid, ferulic acid, p-Coumaric acid, protocatechuic acid, catechin, epicatechin, luteolin, apigenin, myricetin, kaempferol, and quercetin, some of them also found in lower concentrations [18]. Moreover, as confirmed here, Buriti seems to be an excellent source of carotenoids $(44600 \mu \mathrm{g} / 100 \mathrm{~g})$, especially $\alpha$ - and $\beta$-carotene and cis- and trans-áț-carotene [40-43], which are normally found in carrots and are considered the most known and accepted source by consumers, justifying its use to treat hypovitaminosis A.

Our results presented differences per $100 \mathrm{~g}$ of dry material, since Buriti samples were collected under natural conditions from Cerrado Brazilian (a type of savanna) and most studies presented outcomes with fruits from Amazon region. These findings are explained by differences in biome conditions. Amazon is hot and humid, while Cerrado presents a dryer climate. Besides, the Cerrado soil is more acid and rich in aluminum salts, which will probably generate 
higher oxidative stress for the plants. They react, producing antioxidant agents [41].

Polyphenol substances with high in vitro antioxidant activity do not necessarily have similar actions after gastrointestinal process and absorption [20,44]. Therefore, we verified the bioaccessibility of phenolic compounds from pulp, peel, and endocarp methanol extracts. For this, we used an in vitro method that has recently gained much attention because it simulates the process of gastrointestinal digestion, enabling studying changes that occur in the diet components during gastric and intestinal digestion. Moreover, in vitro techniques have the advantage to substitute animals and are time-efficient and cost-effective and require less manpower [21, 23, 44, 45]. Interestingly, M. flexuosa methanol extracts showed reduction of bioaccessible polyphenols after digestion simulation ranging from 18.7 (pulp) to $38.7 \%$ (peel).

It is important to note that only solubilized nutrients from the food matrix which are not destroyed during gastrointestinal digestion are bioaccessible and potentially bioavailable $[22,23]$. Since dietary fiber components are not absorbed, they achieve the large intestine and provide the substrate for intestinal digestion. Soluble fibers are usually fermented quickly, while insoluble fibers are slowly or only partially fermented. The fermentation is carried out by anaerobic bacteria of the colon (e.g., Lactobacillus and Bifidobacterium genera), leading to the production of lactic acid, short-chain fatty acids, and gas, events that can alter food components and their bioavailability [46]. Furthermore, the consumption of high quantities of phytates and oxalates can cause chelation of metal ions (e.g., calcium and zinc) and induce cholelithiasis [24].

Although M. flexuosa fruits have been associated with multiple nutritional properties that can be favorable to the human health, their fibers and polyphenols may link to macromolecular compounds that are not dialyzable or generate mineral complexes, further decreasing solubility and bioaccessibility of phenols [47, 48]. Furthermore, because dialysis process during in vitro gastrointestinal digestion separates bioactive substances, this can interfere with biological activity and quantity of phenolic compounds, which may work more efficiently together rather than individually as synergists to reduce free radicals [49].

Investigators working with cashew fruits from Anacardium occidentale L., another typical natural delight from Brazilian Northeast known as "caju," "acajuíba," and "açajaíba," but more popular, accepted, studied, and economically exploited than $M$. flexuosa, also showed a considerable loss of phenolic compounds in cashew apple juice and cashew apple fiber after bioaccessibility tests, mainly due to the type of food matrix elements, and this often alters absorption of phenolic compounds [44].

In vitro antioxidant activity is mainly based on chemical assays that assess the ability of a substance to reduce the concentration of free radicals in a specific reaction medium $[50,51]$. Then, we performed methods to determine the in vitro scavenging actions.

Firstly, we used the DPPH method, since it is a rapid, simple, accurate, and inexpensive assay for measuring the ability of different compounds to act as free radical scavengers or hydrogen donors and to evaluate the antioxidant activity of foods and beverages independent of sample polarity [11, 52]. In the ABTS test, 2,2' -azino-bis (3-ethylbenzthiazoline6 -acid) (ABTS) is converted into its radical $\left(\mathrm{ABTS}^{\circ+}\right)$ by addition of sodium persulphate and is reactive towards most antioxidants. Since it is not affected by ionic strength, it can be used to determine both hydrophilic and hydrophobic antioxidant capacities [10]. The total antioxidant activity was also measured by the ferric reducing antioxidant power assay. Flavonoids and phenolic acids presented in the medicinal plants exhibit strong antioxidant activity, which is depending on their potential to form the complex with metal atoms, particularly iron and copper. This method is based on the principle of increase in the absorbance of the reaction mixtures [32]. Subsequently, lipid peroxidation was determined by TBARS removal. Since polyunsaturated fatty acids are easy targets for oxidants, and the process of lipid peroxidation is, once initiated, a self-sustaining free radical chain process, the accumulation of lipid peroxidation products provides the most common biochemical marker of oxidative stress $[33,34]$. Finally, nitrite ion technique was carried out based on the decomposition of sodium nitroprusside in nitric oxide at physiological $\mathrm{pH}$, under aerobic conditions, which produces nitrites $[35,36]$. It was important to perform the evaluation of samples against RNS, since these radicals may cause damage to biological components such as the aromatic amino acid tyrosine and DNA bases, particularly in guanines, by nitration or hydroxylation [51].

Buriti samples presented antioxidant capacity, and peel extracts were more active scavengers. References [14] also demonstrated antioxidant potential in leaves (iron reduction test) and fruit pulps (DPPH method) from Mauritia flexuosa. Differences in the antioxidant action found are probably associated with distinctive concentrations of the chemical constituents in each part of the plant, mainly flavonoids and anthocyanins [53]. So, there is a huge possibility that this effect repeats in Buriti fruits in different Brazilian regions, once M. flexuosa in the "Cerrado" biome is exposed to a higher incidence of sunlight in a soil of dry climate [54]. It is supposed that climate conditions interfere even in the constitution of the general parts, with average values of $22.1-25.1,11-24.2,21.0$, and $32.6-63.9 \%$ for peel, pulp, endocarp, and seed, respectively $[25,55]$.

Typically, phenols and carotenoids are found in higher concentrations in peels due to their pigmentation, regulation of enzymatic activity, and protection against sunlight and pathogenic microorganisms $[1,56]$. So, we noted superior presence of phenolic compounds (57.0 and 53.6\%), flavonoids (22.1 and 57.2\%), tannins (hydrolysable: 15.7 and 99.8\%; condensed: 41.1 and 69.1\%), and ascorbic acid levels in peels when compared to pulp and endocarp, respectively, which improved antioxidant activity in peels, respectively. Taking into consideration the fact that the Dietary Reference Intake (DRI) of ascorbic acid for adults is $45 \mathrm{mg} / \mathrm{day}$ [57], one cup with $200 \mathrm{~mL}$ of peel extract from $M$. flexuosa fruits $(11.7 \mathrm{mg} / \mathrm{mL})$ would correspond to $26 \%$ of the RDI, while consumption of pulp would reach $19.1 \%$. Anyway, it is important to note that vitamin $\mathrm{C}$ is converted to oxalate when it is present in higher concentrations [24]. 
For M. flexuosa fruit, protection by antioxidant compounds is required and could be a reason for the higher concentration of bioactive compounds found in the peel than in pulp and endocarp. Using Pearson's correlation, we found a good correlation index among bioactive compounds and antioxidant capacity for pulp, peel, and endocarp from Mauritia flexuosa, which supports the suggestion that protection against oxidative hemolysis is directly associated with levels of bioactive substances.

Since vegetal extracts are rich in different classes of compounds that can attack or interact with cellular membranes, hemolysis assay is frequently used to test materials, compounds, or mixture of compounds at defined $\mathrm{pHs}$ that mimic extracellular environments. So, the evaluation of membrane stability during exposure to phytotherapeutic products must be routinely considered in their evaluation, since the consumption of these products is increasing globally and may constitute a serious public health problem. So, membrane stability represents the capacity of this biological complex to maintain its structure under chaotropic conditions such as hypotonicity, $\mathrm{pH}$ extremes, heat, and the presence of solutes (such as ethanol, urea, and guanidine) and oxidative stress $[38,58-60]$. When submitted to the cell assays, none of the Buriti samples caused lysis of erythrocytes and reversed hemolysis induced by peroxyl radicals and, once again, better results were found with peel extracts.

The antihemolytic action described for fruit extracts from M. flexuosa may be associated with an osmotic stabilization of erythrocytes. It is possible that the exacerbation of Van der Waals contacts inside the lipid bilayer could be a source of membrane stabilization, though such membrane protection is normally related to the prevention of lipoperoxidation triggered by secondary metabolites such as flavonoids and phenols that can be incorporated into erythrocyte membranes [39, 58, 61]. Indeed, there is a strong correlation between thiobarbituric acid-reactive substances (TBARS) as a marker of lipid peroxidation and products that protect cells against oxidative damage [50]. Such protection can explain, at least in part, some folk uses and pharmacological properties of these fruits, such as protective effects against cognitive impairment $[24,62]$, antiplatelet, antithrombotic [63], lowering cholesterol [43, 64], and healing [19, 41] activities.

\section{Conclusions}

In summary, the antioxidant analysis of $M$. flexuosa fruits and their by-products showed promising chemopreventive potentialities, and peels demonstrated higher quantities of bioactive compounds and phenolic substances before and after in vitro bioaccessibility investigation. Since the processing of $M$. flexuosa fruits generates a large quantity of agricultural residues such as peels, endocarps, and seeds, most of them are commonly discarded or are used as feed for ruminant animals only, especially after production of sweets and oil extraction. Consequently, it is extremely important to explore the nutritional characteristics of these by-products for human/livestock foods and to install biofriendly techniques and sustainable biotechnology handling of natural resources. For Brazilian local communities, it is really important to reuse such residues, especially for people from poor regions, as a way to give better opportunities and improve quality of life.

\section{Data Availability}

The data used to support the findings of this study are available from the corresponding author upon request.

\section{Conflicts of Interest}

All authors declare that there are no conflicts of interest.

\section{Acknowledgments}

This research was partially funded by the public Brazilian agency "Fundação do Amparo à Pesquisa do Estado do Piauí" [FAPEPI (Grant no. 004/2016)]. The corresponding author is grateful to Conselho Nacional de Desenvolvimento Científico e Tecnológico" [CNPq (\#305086/2016-2)] for the personal scholarship.

\section{References}

[1] M. Murkovic, "Phenolic compounds: occurrence, classes, and analysis," in The Encyclopedia of Food and Health, B. Caballero, P. Finglas, and F. Toldrá, Eds., pp. 346-351, 2016.

[2] C. C. Benz and C. Yau, "Ageing, oxidative stress and cancer: paradigms in parallax," Nature Reviews Cancer, vol. 8, no. 11, pp. 875-879, 2008.

[3] G. L. D. S. Oliveira, A. L. Gomes-J, R. M. Freitas et al., "Assessment of antioxidant capacity in vitro and in vivo of the ethanol extract of Copernicia prunifera (Mill.) HE Moore," Revista Bßsica e Aplicada, vol. 35, no. 2, pp. 293-300, 2015.

[4] É. J. F. de Araújo, G. A. L. de Oliveira, L. Q. de Sousa et al., "Counteracting effects on free radicals and histological alterations induced by a fraction with casearins," Anais da Academia Brasileira de Ciências, vol. 87, no. 3, pp. 1791-1807, 2015.

[5] G. P. Morais, M. V. O. B. Alencar, T. Islam et al., "Cytogenotoxic and oxidative status evaluation of Morinda citrifolia," International Archives of Medicine, vol. 9, no. 96, pp. 1-13, 2016.

[6] J. A. Tur and M. M. Bibiloni, "Functional foods," in The Encyclopedia of Food and Health, B. Caballero, P. Finglas, and F. Toldrá, Eds., pp. 157-161, 2016.

[7] T. Srdić-Rajić and A. Konić Ristić, "Antioxidants: role on health and prevention," in The Encyclopedia of Food and Health, B. Caballero, P. Finglas, and F. Toldrá, Eds., pp. 227-233, 2016.

[8] J. A. Rodríguez-Sánchez, M. T. Cruz y Victoria, and B. E. Barragán-Huerta, "Betaxanthins and antioxidant capacity in Stenocereus pruinosus: Stability and use in food," Food Research International, vol. 91, pp. 63-71, 2017.

[9] D. Krishnaiah, R. Sarbatly, and R. Nithyanandam, "A review of the antioxidant potential of medicinal plant species," Food and Bioproducts Processing, vol. 89, no. 3, pp. 217-233, 2011.

[10] C. López-Alarcón and A. Denicola, "Evaluating the antioxidant capacity of natural products: a review on chemical and cellularbased assays," Analytica Chimica Acta, vol. 763, pp. 1-10, 2013.

[11] D. F. Farias, T. M. Souza, M. P. Viana et al., "Antibacterial, antioxidant, and anticholinesterase activities of plant seed 
extracts from Brazilian semiarid region," BioMed Research International, vol. 2013, Article ID 510736, 9 pages, 2013.

[12] J. A. Pereira-Freire, K. B. N. T. Barros, L. K. F. Lima et al., "Phytochemistry profile, nutritional properties and pharmacological activities of Mauritia flexuosa," Journal of Food Science, vol. 81, pp. 2611-2622, 2016.

[13] T. L. Chaves, L. Ricardo, J. de Paula-Souza, and M. D. G. L. Brandão, "Useful Brazilian plants under the view of the writer-naturalist João Guimarães Rosa," Revista Brasileira de Farmacognosia, vol. 25, no. 5, pp. 437-444, 2015.

[14] H. H. F. Koolen, F. M. A. da Silva, F. C. Gozzo, A. Q. L. de Souza, and A. D. L. de Souza, "Antioxidant, antimicrobial activities and characterization of phenolic compounds from buriti (Mauritia flexuosa L. f.) by UPLC-ESI-MS/MS," Food Research International, vol. 51, no. 2, pp. 467-473, 2013.

[15] H. H. Koolen, E. R. Soares, F. M. da Silva et al., "Mauritic acid: a new dammarane triterpene from the roots of " Natural Product Research (Formerly Natural Product Letters), vol. 27, no. 22, pp. 2118-2125, 2013.

[16] E. P. Siqueira, A. A. Andrade, E. M. Souza-Fagundes et al., "In vitro antibacterial action on methicillin susceptible (MSSA) and methicillin-resistant (MRSA) Staphylococcus aureus and antitumor potential of Mauritia flexuosa L. f," Journal of Medicinal Plants Research, vol. 8, no. 48, pp. 1408-1417, 2014.

[17] J. S. Aquino, D. C. N. D. Pessoa, K. L. G. V. Araújo et al., "Refining of buriti oil (Mauritia flexuosa L.) originated from the Brazilian Cerrado: physicochemical, thermal-oxidative and nutritional implications," Journal of the Brazilian Chemical Society, vol. 23, no. 2, pp. 212-219, 2012.

[18] G. A. Bataglion, F. M. A. da Silva, M. N. Eberlin, and H. H. F. Koolen, "Simultaneous quantification of phenolic compounds in buriti fruit (Mauritia flexuosa L.f.) by ultra-high performance liquid chromatography coupled to tandem mass spectrometry," Food Research International, vol. 66, pp. 396-400, 2014.

[19] J. S. Batista, R. G. Olinda, V. B. Medeiros et al., "Atividade antibacteriana e cicatrizante do óleo de buriti Mauritia flexuosa L.," Ciência Rural, vol. 42, no. 1, pp. 136-141, 2012.

[20] V. Briones-Labarca, G. Venegas-Cubillos, S. Ortiz-Portilla, M. Chacana-Ojeda, and H. Maureira, "Effects of high hydrostatic pressure (HHP) on bioaccessibility, as well as antioxidant activity, mineral and starch contents in Granny Smith apple," Food Chemistry, vol. 128, no. 2, pp. 520-529, 2011.

[21] H. Palafox-Carlos, J. F. Ayala-Zavala, and G. A. GonzálezAguilar, "The role of dietary fiber in the bioaccessibility and bioavailability of fruit and vegetable antioxidants," Journal of Food Science, vol. 76, no. 1, pp. R6-R15, 2011.

[22] J. Parada and J. M. Aguilera, "Food microstructure affects the bioavailability of several nutrients," Journal of Food Science, vol. 72, no. 2, pp. R21-R32, 2007.

[23] D. Tagliazucchi, E. Verzelloni, D. Bertolini, and A. Conte, "In vitro bio-accessibility and antioxidant activity of grape polyphenols," Food Chemistry, vol. 120, no. 2, pp. 599-606, 2010.

[24] I. M. Cattani and J. Baruque-Ramos, "Brazilian Buriti palm fiber (Mauritia flexuosa Mart.)," in Natural Fibres: Advances in Science and Technology Towards Industrial Applications: From Science to Market, R. Fangueiro and S. Rana, Eds., pp. 89-98, Springer, Dordrecht, Netherlands, 2016.

[25] B. T. Carneiro and J. G. M. Carneiro, "Fruit and pulp buriti (Mauritia flexuosa L.): physical, chemical and technological aspects," Revista Verde, vol. 6, pp. 105-111, 2011.
[26] Q. Zhang, W. Chen, J. Zhao, and W. Xi, "Functional constituents and antioxidant activities of eight Chinese native goji genotypes," Food Chemistry, vol. 200, pp. 230-236, 2016.

[27] R. B. Broadhurst and W. T. Jones, "Analysis of condensed tannins using acidified vanillin," Journal of the Science of Food and Agriculture, vol. 29, no. 9, pp. 788-794, 1978.

[28] C. M. Bossu, E. C. Ferreira, F. S. Chaves, E. A. Menezes, and A. R. A. Nogueira, "Flow injection system for hydrolysable tannin determination," Microchemical Journal, vol. 84, no. 1-2, pp. 8892, 2006.

[29] N. C. De Moura and S. G. Canniatti-Brazaca, "Evluation of iron availabilty of the common bean in comparson with bovine meat," Ciência e Tecnologia de Alimentos, vol. 26, no. 2, pp. 270276, 2006.

[30] W. Brand-Williams, M. E. Cuvelier, and C. Berset, "Use of a free radical method to evaluate antioxidant activity," LWT - Food Science and Technology, vol. 28, no. 1, pp. 25-30, 1995.

[31] R. Re, N. Pellegrini, A. Proteggente, A. Pannala, M. Yang, and C. Rice-Evans, "Antioxidant activity applying an improved ABTS radical cation decolorization assay," Free Radical Biology \& Medicine, vol. 26, no. 9-10, pp. 1231-1237, 1999.

[32] G. K. B. Lopes, H. M. Schulman, and M. Hermes-Lima, "Polyphenol tannic acid inhibits hydroxyl radical formation from Fenton reaction by complexing ferrous ions," Biochimica et Biophysica Acta (BBA) - General Subjects, vol. 1472, no. 1-2, pp. 142-152, 1999.

[33] H. Esterbauer and K. H. Cheeseman, "Determination of aldehydic lipid peroxidation products: malonaldehyde and 4hydroxynonenal," Methods in Enzymology, vol. 186, pp. 407-421, 1990.

[34] A. G. Guimarães, G. F. Oliveira, M. S. Melo et al., "Bioassayguided evaluation of antioxidant and antinociceptive activities of carvacrol," Clinical Pharmacology \& Toxicology, vol. 107, no. 6, pp. 949-957, 2010.

[35] L. C. Green, S. R. Tannenbaum, and P. Goldman, "Nitrate synthesis in the germfree and conventional rat," Science, vol. 212, no. 4490 , pp. 56-58, 1981.

[36] S. Basu and B. Hazra, "Evaluation of nitric oxide scavenging activity, in vitro and ex vivo, of selected medicinal plants traditionally used in inflammatory diseases," Phytotherapy Research, vol. 20, no. 10, pp. 896-900, 2006.

[37] É. J. F. D. Araújo, L. K. F. Lima, O. A. Silva et al., "In vitro antioxidant, antitumor and leishmanicidal activity of riparin A, an analog of the Amazon alkamides from Aniba riparia (Lauraceae)," Acta Amazonica, vol. 46, no. 3, pp. 309-314, 2016.

[38] d. Carvalho, "Biological screening of extracts of Brazilian Asteraceae plants," African Journal of Pharmacy and Pharmacology, vol. 7, no. 28, pp. 2000-2005, 2013.

[39] R. L. M. de Freitas, G. L. da Silva Oliveira, R. M. de Freitas et al., "In vitro effects of arylhydrocoumarin on free radicals and oxidative stress in erythrocytes and Saccharomyces cerevisiae," Current Pharmaceutical Biotechnology, vol. 15, no. 11, pp. 10691082, 2014.

[40] A. L. D. S. Lima, K. D. S. C. Lima, M. J. Coelho, J. M. Silva, R. L. D. O. Godoy, and P. Sidney, "Evaluation of gamma irradiation effects on carotenoids, ascorbic acid and sugar contents of Buriti fruit (Mauritia flexuosa L.)," Acta Amazonica, vol. 39, no. 3, pp. 649-654, 2009.

[41] T. L. N. Cândido, M. R. Silva, and T. S. Agostini-Costa, "Bioactive compounds and antioxidant capacity of buriti (Mauritia flexuosa L.f.) from the Cerrado and Amazon biomes," Food Chemistry, vol. 177, pp. 313-319, 2015. 
[42] M. D. F. G. Santos, R. V. S. Mamede, M. D. S. M. Rufino et al., "Amazonian Native Palm Fruits as Sources of Antioxidant Bioactive Compounds," Antioxidants, vol. 4, no. 3, pp. 591-602, 2015.

[43] J. S. Aquino, M. H. A. Aquino, D. C. N. P. Pessoa et al., "Intake of cookies made with buriti oil (Mauritia flexuosa) improves vitamin A status and lipid profiles in young rats," Food \& Function: Royal Society of Chemistry, vol. 7, no. 10, pp. 44424450, 2016.

[44] A. C. S. De Lima, D. J. Soares, L. M. R. Da Silva, R. W. De Figueiredo, P. H. M. De Sousa, and E. De Abreu Menezes, "In vitro bioaccessibility of copper, iron, zinc and antioxidant compounds of whole cashew apple juice and cashew apple fibre (Anacardium occidentale L.) following simulated gastrointestinal digestion," Food Chemistry, vol. 161, pp. 142-147, 2014.

[45] B. R. Shah, C. Zhang, Y. Li, and B. Li, "Bioaccessibility and antioxidant activity of curcumin after encapsulated by nano and Pickering emulsion based on chitosan-tripolyphosphate nanoparticles," Food Research International, vol. 89, pp. 399407, 2016.

[46] S. M. I. Saad, "Probiotics and prebiotics: the state of the art," Revista Brasileira de Ciências Farmacêuticas, vol. 42, no. 1-6, 2006.

[47] L. R. T. Manhães and A. U. O. Sabaa-Srur, "Centesimal composition and bioactive compounds in fruits of buriti collected in pará," Ciência e Tecnologia de Alimentos, vol. 31, no. 4, pp. 856863, 2011.

[48] J. Bouayed, L. Hoffmann, and T. Bohn, "Total phenolics, flavonoids, anthocyanins and antioxidant activity following simulated gastro-intestinal digestion and dialysis of apple varieties: Bioaccessibility and potential uptake," Food Chemistry, vol. 128, no. 1, pp. 14-21, 2011.

[49] U. Gawlik-Dziki, M. Jezyna, M. Świeca, D. Dziki, B. Baraniak, and J. Czyz, "Effect of bioaccessibility of phenolic compounds on in vitro anticancer activity of broccoli sprouts," Food Research International, vol. 49, no. 1, pp. 469-476, 2012.

[50] A. V. Badarinath, K. M. Rao, C. M. S. Chetty, S. Ramkanth, T. V. S. Rajan, and K. Gnanaprakash, "A review on in-vitro antioxidant methods: comparisions, correlations and considerations," International Journal of PharmTech Research, vol. 2, no. 2, pp. 1276-1285, 2010.

[51] M. Carocho and I. C. F. R. Ferreira, "A review on antioxidants, prooxidants and related controversy: natural and synthetic compounds, screening and analysis methodologies and future perspectives," Food and Chemical Toxicology, vol. 51, no. 1, pp. 15-25, 2013.

[52] K. Marxen, K. H. Vanselow, S. Lippemeier, R. Hintze, A. Ruser, and U.-P. Hansen, "Determination of DPPH radical oxidation caused by methanolic extracts of some microalgal species by linear regression analysis of spectrophotometric measurements," Sensors, vol. 7, no. 10, pp. 2080-2095, 2007.

[53] B. S. Ferreira, C. G. De Almeida, L. P. Faza et al., "Comparative properties of amazonian oils obtained by different extraction methods," Molecules, vol. 16, no. 7, pp. 5874-5885, 2011.

[54] K. Mori, N. Goto-Yamamoto, M. Kitayama, and K. Hashizume, "Loss of anthocyanins in red-wine grape under high temperature," Journal of Experimental Botany, vol. 58, no. 8, pp. 19351945, 2007.

[55] R. L. Barbosa, A. D. Lima, and M. M. Junior, Biometria de frutos do buriti (Mauritia flexuosa L.f. Arecaceae): estimativas de produtividade de polpa e óleo vegetal em uma área de savana em Roraima, INPA, CPEC, Amazônia, Brazil, 2009.
[56] R. K. Saini, S. H. Nile, and S. W. Park, "Carotenoids from fruits and vegetables: Chemistry, analysis, occurrence, bioavailability and biological activities," Food Research International, vol. 76, pp. 735-750, 2015.

[57] N. Martí, P. Mena, J. A. Cánovas, V. Micol, and D. Saura, "Vitamin C and the role of citrus juices as functional food," Natural Product Communications (NPC), vol. 4, no. 5, pp. 677700, 2009.

[58] P. Sharma and J. D. Sharma, "In vitro hemolysis of human erythrocytes by plant extracts with antiplasmodial activity," Journal of Ethnopharmacology, vol. 74, no. 3, pp. 239-243, 2001.

[59] M. Roselli, M. S. Britti, I. Le Huërou-Luron, H. Marfaing, W. Y. Zhu, and E. Mengheri, "Effect of different plant extracts and natural substances (PENS) against membrane damage induced by enterotoxigenic Escherichia coli K88 in pig intestinal cells," Toxicology in Vitro, vol. 21, no. 2, pp. 224-229, 2007.

[60] A. Ceriello, R. Testa, and S. Genovese, "Clinical implications of oxidative stress and potential role of natural antioxidants in diabetic vascular complications," Nutrition, Metabolism \& Cardiovascular Diseases, vol. 26, no. 4, pp. 285-292, 2016.

[61] S. Chaudhuri, A. Banerjee, K. Basu, B. Sengupta, and P. K. Sengupta, "Interaction of flavonoids with red blood cell membrane lipids and proteins: antioxidant and antihemolytic effects," International Journal of Biological Macromolecules, vol. 41, no. 1, pp. 42-48, 2007.

[62] L. K. R. Leão, A. M. Herculano, C. Maximino et al., "Mauritia flexuosa L. protects against deficits in memory acquisition and oxidative stress in rat hippocampus induced by methylmercury exposure," Nutritional Neuroscience, vol. 20, no. 5, pp. 297-304, 2016.

[63] E. Fuentes, W. Rodríguez-Pérez, L. Guzmán et al., "Mauritia flexuosa presents in vitro and in vivo antiplatelet and antithrombotic activities," Evidence-Based Complementary and Alternative Medicine, vol. 2013, Article ID 653257, 11 pages, 2013.

[64] J. De Souza Aquino, J. K. B. Soares, M. Magnani et al., "Effects of dietary brazilian palm oil (Mauritia flexuosa L.) on Cholesterol profile and Vitamin A and e status of rats," Molecules, vol. 20, no. 5, pp. 9054-9070, 2015. 


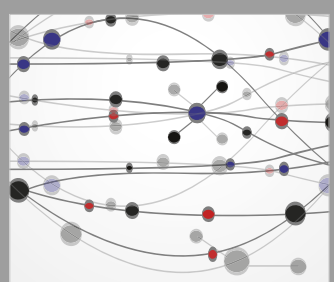

The Scientific World Journal
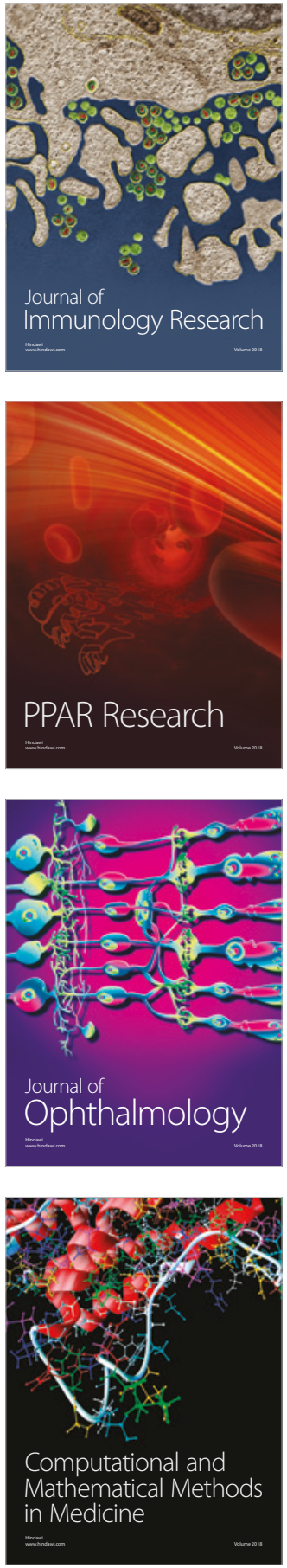

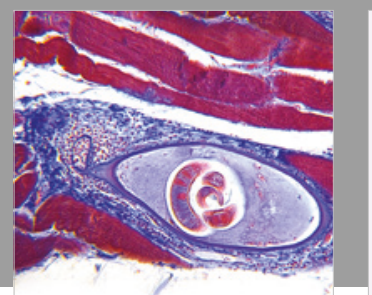

Gastroenterology Research and Practice

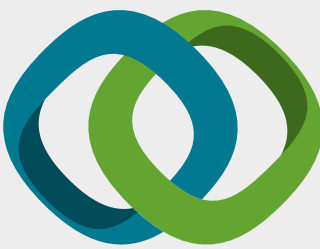

\section{Hindawi}

Submit your manuscripts at

www.hindawi.com
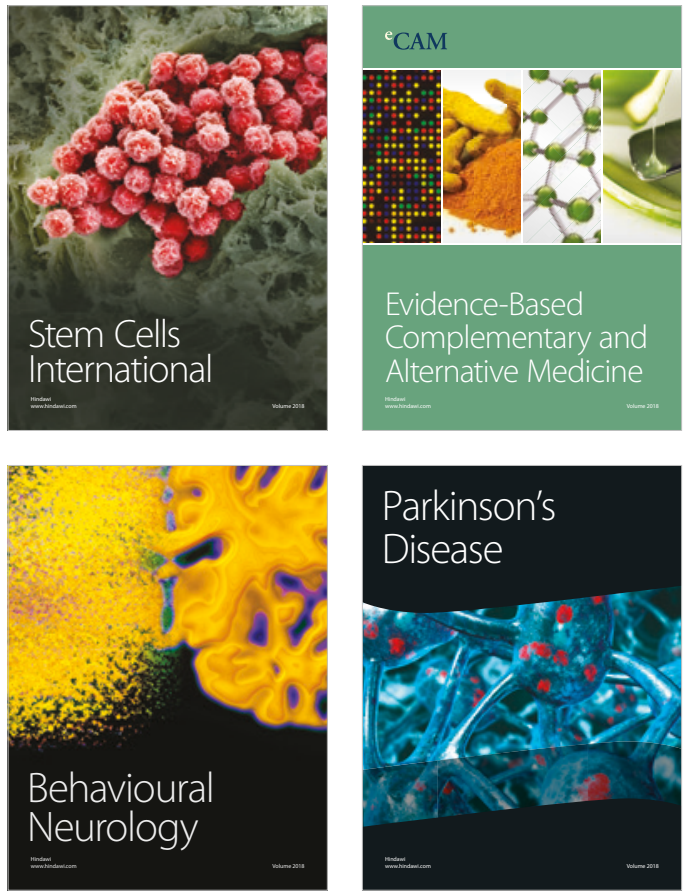

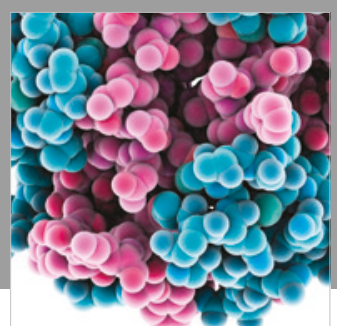

ournal of

Diabetes Research

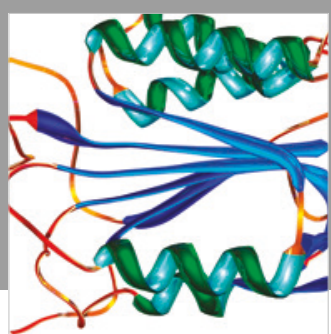

Disease Markers
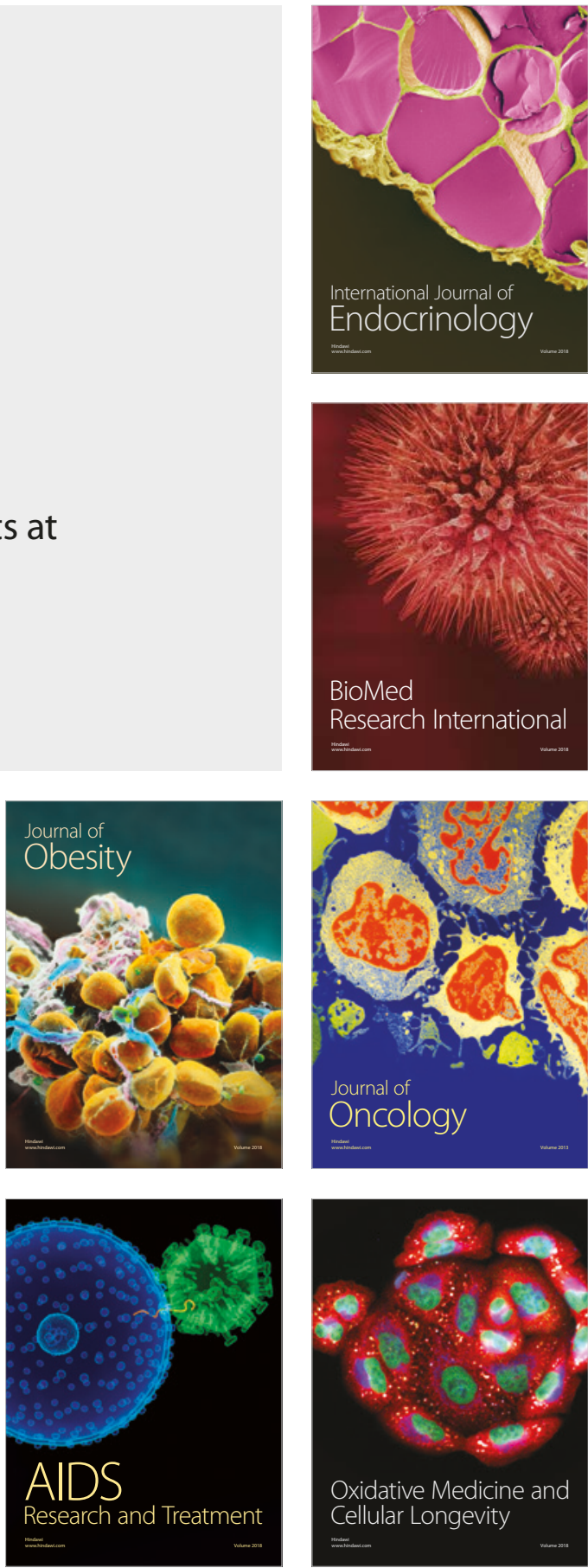